\title{
Carbon Nanotubes Modified Carbon Cloth Cathode Electrode for Self-Pumping Enzymatic Biofuel Cell
}

\author{
Ngoc Bich Duong, ${ }^{1}$ Sheng L. You, ${ }^{1}$ Li Z. Huang, ${ }^{1}$ and Hsiharng Yang $\mathbb{D}^{1,2}$ \\ ${ }^{1}$ Graduate Institute of Precision Engineering, National Chung Hsing University, Taichung City 402, Taiwan \\ ${ }^{2}$ Innovation and Development Center of Sustainable Agriculture (IDCSA), National Chung Hsing University, \\ 145 Xingda Road, Taichung City 402, Taiwan
}

Correspondence should be addressed to Hsiharng Yang; hsiharng@nchu.edu.tw

Received 27 December 2017; Revised 24 April 2018; Accepted 25 June 2018; Published 9 July 2018

Academic Editor: Abhijeet P. Borole

\begin{abstract}
Copyright (C) 2018 Ngoc Bich Duong et al. This is an open access article distributed under the Creative Commons Attribution License, which permits unrestricted use, distribution, and reproduction in any medium, provided the original work is properly cited.

A self-pumping enzymatic biofuel cell (self-pumping EBC) with a new cathodic catalyst which was modified by coating the mixture of carbon nanotubes/caffeic acid (CNTs/CA) on a carbon cloth (CC) to form a CNTs/CA/CC cathode electrode was fabricated. By using UV spectrophotometer, the absorbance of CA, CNTs, and the CNTs/CA composite was observed. To evaluate how the $\mathrm{CNTs} / \mathrm{CA} / \mathrm{CC}$ cathodic electrode improves the electrochemical performance of the self-pumping EBC, the measurement of the redox reaction current peak by cyclic voltammetry $(\mathrm{CV})$ was implemented. In accordance with $\mathrm{CV}$ measurement, the utilization of the modified CNTs/CA/CC cathodic electrode exhibited a higher oxygen reduction current peak at 319.1 $\mu \mathrm{A}$ under the saturated oxygen. The anode and cathode flow rates were $0.416 \mu \mathrm{ls}^{-1}$ and $0.844 \mu \mathrm{ls}^{-1}$ which contribute to obtaining the capillary driven liquid efficiency as 30\% for the former and 59\% for the latter. Moreover, the self-pumping EBC performance tests showed that the maximum power density (MPD) of the self-pumping EBC with the modified cathodic electrode achieved $0.592 \mathrm{mWcm}^{-2}$ which improved $10 \%$ in the performance compared with the bare CC electrode, $0.534 \mathrm{mWcm}^{-2}$.
\end{abstract}

\section{Introduction}

Biofuel cell converts chemical energy into electrical energy through a series of biochemical reactions by utilizing biocatalyst. Compared to many traditional environment-friendly energy sources, such as wind power, solar power, and geothermal power generation, the biofuel cell (BFC) is a growing alternative energy source. According to the type of catalyst, the biofuel cell can be separated into the fuel cell as microbial biofuel cell (MBC) that uses micro bacteria to react for electricity and enzymatic biofuel cell (EBC) that employs enzymes as a catalyst to separate electrons from parent molecule and force it to go around an electrolyte barrier through a wire to generate an electric current. This study is focusing on the EBC type that produces higher electrochemical performance and more simple structure compared to the MBC $[1,2]$.

The unique characteristic of the EBCs is that enzymes are used as biocatalysts in the redox reaction such as glucose dehydrogenase $[3,4]$, glucose oxidase [5-7], laccase [8, 9], and alcohol dehydrogenase [10]. The mechanism for oxidizing GOx is described in Figure 1. The GOx immobilized on the anode surface reacts with glucose to produce protons and electrons while the incoming electrons moving from the anode to the cathode electrode via the external circuit decrease the ferricyanide $\left(\mathrm{Fe}[\mathrm{CN}]_{6}{ }^{3-}\right)$ to ferrocyanide $\left(\mathrm{Fe}[\mathrm{CN}]_{6}{ }^{4-}\right)$. Simultaneously, protons that migrate through the Nafion ${ }^{5} 117$ membrane to the cathode compartment reduce oxygen to water and reoxidize ferrocyanide to ferricyanide.

Chitosan (CS) is a physicochemical biopolymer for enzyme immobilization with the attractive properties such as an excellent film-forming ability and a good adhesion, nontoxicity, and biocompatibility [11]. Y. Zhang and coworkers [12] developed a new glucose biosensor by coating CS as a protection film on the surface of GOx. B. K. Shrestha et al. [13] succeeded in fabricating the electrode immobilized 


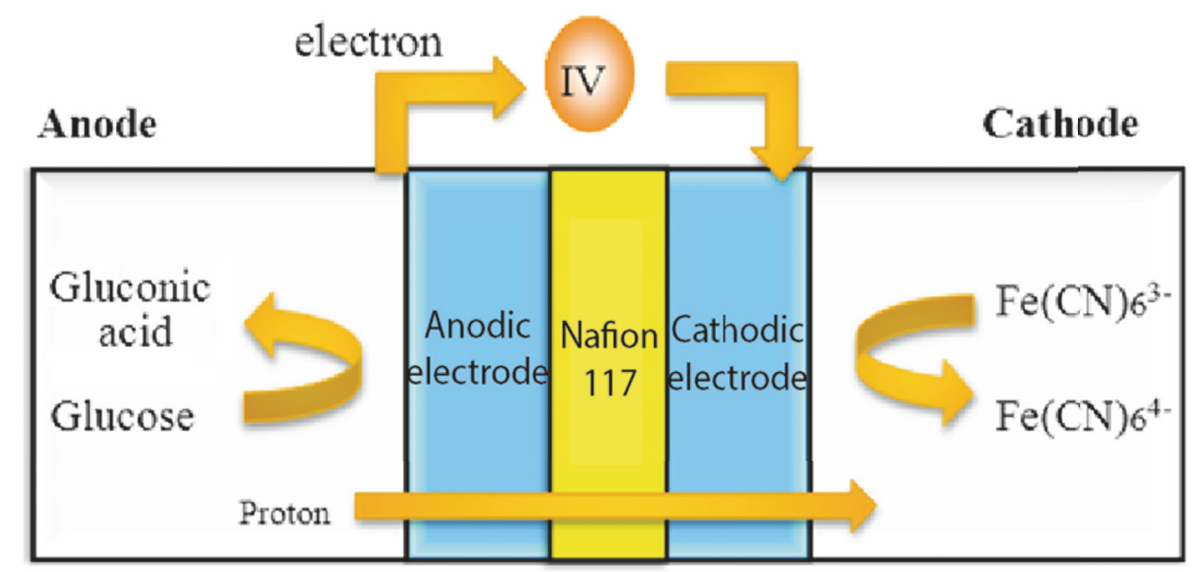

FIGURE 1: Enzymatic biofuel cell schematic showed the major components and its basic operation.

CS-GOx on its surface to achieve a high-performance glucose biosensor.

Carbon nanotubes (CNTs) electrode and modified carbon electrode, the prominent materials for their application in bioanalytical devices, are particularly appropriate to establish an efficient electrical communication between enzymes and electrode $[5-7,14]$. The research of A.B. Moghaddam and coauthors [15] indicated that SWCNT with graphite-based electrode offered an improvement in the CA electrochemical behavior and investigated the influence of the scan rate in the CA oxidation by CV measurement. With the presence of CA, the anodic and cathodic peak was 17-fold higher than that of a bare GCE [16].

Based on the fuel delivery mechanism, the fuel cell system is divided into an active system and passive system using an extra pump and capillary effect, respectively. The input power of the pump in the active ones is sometimes much larger than that of their output power. On the other hand, the delivered fuel in the passive system works through the capillary effect [17]; the fuel concentration gradient diffuses into the anode component [18]; the cohesion and adhesion pressure causes the liquid fuel to work against the gravity [19]. In our previous research, Y.F. Tsai and H. Yang [20] successfully turned out a new research direction that their fabricated EBC can drive fuel by itself through the capillary effect named self-pumping enzymatic fuel cell whose maximum power density was quite low.

With the above information, in this study, the selfpumping $\mathrm{EBC}$ is with a modified $\mathrm{CC}$ at the cathode and anode electrode CNTs/CA/CC and GOx[TPP/CS/CC], respectively, to enhance the self-pumping EBC's electricity. The GOx[TPP/CS/CC] electrode was prepared by the same method in the previous study [20], where CS solution was coated on the surface of the anodic electrode as an adhesion film to ensure the stability and biocompatibility of the enzyme GOx on the electrode surface. The fabricating process of the new catalyst attached to the cathode electrode CNTs/CA/CC is described in Section 2.3. Whether the CNTs/CA can improve the redox current as well as the power output of the self-pumping EBC through several methods such as UV spectrophotometer, $\mathrm{CV}$ measurement, and polarization test (Tafel test) was evaluated, and the performances of the selfpumping EBC were successfully investigated.

\section{Experimental}

2.1. Materials. Glucose oxidase from Aspergillus niger (Gluzyme Mono ${ }^{\circledR} 10.000$ BG) was obtained from Novo Nordisk Bioindustrials Inc. (Copenhagen, Denmark). Carbon cloth was obtained from CeTech Co. (domestic company). MWCNTs were purchased from Carbon Science and Technology (Taiwan). Caffeic acid (CA) powder was obtained from Sigma-Aldrich. CS powder (MW $140000 \mathrm{dal} / \mathrm{mol}$ ) with $90 \%$ deacetylation and sodium tripolyphosphate (TPP) were purchased from Shin ERA Technology Co., Ltd. (Taiwan). Potassium hexacyanoferrate(III) $\left(\mathrm{K}_{3}\left[\mathrm{Fe}(\mathrm{CN})_{6}\right]\right)$ was obtained from Wako Chemicals (USA). Nafion 117 membranes (DuPont) were pretreated before being applied to the electrode.

2.2. Preparation of Anodic Electrode Immobilized GOx Enzyme. The fabricating process of anodic electrode GOx(TPP/CS/CC) was described previously [20]; however, a short summary will be given for convenience. There were three separate steps in the fabrication process of the anodic electrode. (1) The first step is the preparation of CS carrier acidic solution: dissolving $1 \mathrm{~g}$ of CS in $100 \mathrm{ml}$ of $1 \%(\mathrm{v} / \mathrm{v})$ acetic acid under magnetic stirring is to make the acidic aqueous solution. Simultaneously, $25 \mathrm{mg}$ TPP was added to $25 \mathrm{ml}$ of deionized water (D.I. water) to prepare a $50 \mathrm{wt} \%$ TPP cross-linker aqueous solution, followed by adding the cross-linking agent aqueous solution to the preprepared CS solution and thoroughly stirring the mixture. (2) The second step is the preparation of alkaline solution: $4 \mathrm{~g}$ of $\mathrm{NaOH}$ was added to $100 \mathrm{ml}$ of deionized water to create 1 $\mathrm{M} \mathrm{NaOH}$ solution. A small piece of the acidic pretreated carbon cloth $\left(2 \times 3 \mathrm{~cm}^{2}\right)$ was first immersed in the CS carrier/cross-linking reagent solution and sonicated for 10 min to coat the CS/TPP cross-linked on CC surface followed by transferring the cross-linked $\mathrm{CC}$ into the $\mathrm{NaOH}$ solution 


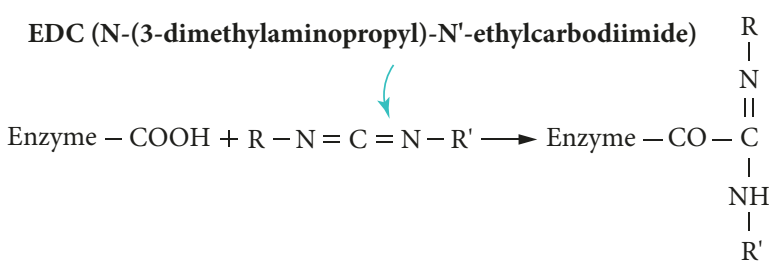

NHS (N-hydroxysuccinimide)

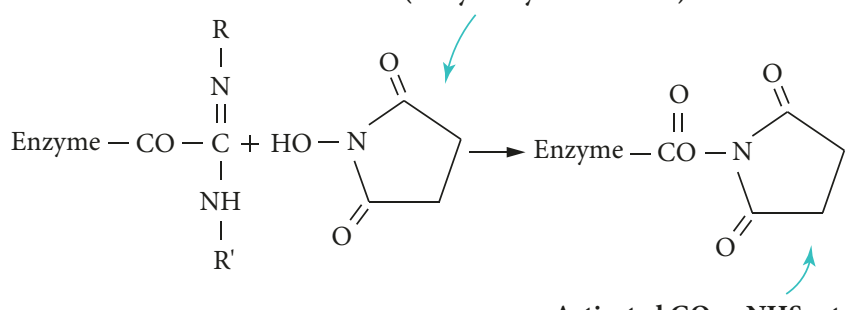

Activated GOx - NHS ester

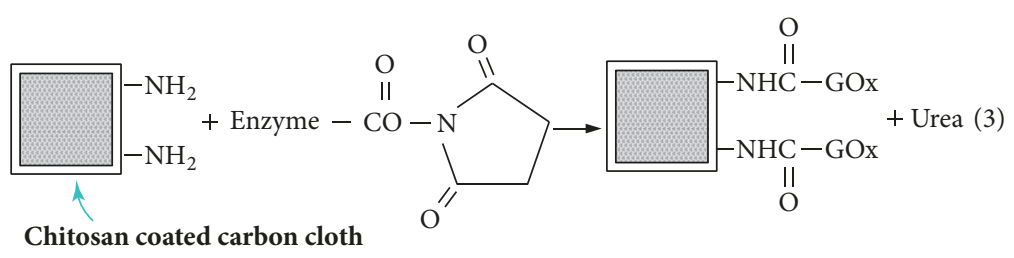

FIGURE 2: EDC, NHS, and GOx reaction mechanism for activated and stabilized enzyme.

to precipitate the coated CS. The washing procedure was repeated 3 times to remove the residue from the $\mathrm{NaOH}$ solution on the surface of the modified CC which was stored in D.I. water for usage. (3) The third step is the immobilization of enzyme GOx (Figure 2): $40 \mathrm{mg}$ GOx was added to the prepared phosphate buffer solution (PBS, $\mathrm{pH}$ $6,50 \mathrm{mM}$ ) and stirred until it was completely dissolved. The GOx solution was continuously mixed with NHS aqueous solution ( $4 \mathrm{mg} / \mathrm{ml}$, stirred at $110 \mathrm{rpm}$ for $1 \mathrm{~h}$ ) and EDC aqueous solution $(2.4 \mathrm{mg} / \mathrm{ml}$, stirred at 110rpm for $1 \mathrm{~h}$ ) for enzyme activation and stabilization [21]. The CS/TPP coated CC was finally immersed in the activated GOx solution.

2.3. Preparation of Cathodic Electrode. For preparing the cathodic electrode CNTs/CA/CC, after CNTs was purified by the acidic treatment that was the mixture of the sulfuric acid $\left(\mathrm{H}_{2} \mathrm{SO}_{4}\right)$ and nitric acid $\left(\mathrm{HNO}_{3}\right)$ at the concentration of 3:1, $10 \mathrm{mM}$ CA was combined with $10 \mathrm{mg} / \mathrm{ml}$ purified CNTs dissolved in $5 \mathrm{ml}$ of ethanol solution and shaken by ultrasonic bath for $16 \mathrm{~h}$. As shown in Figure 3, the bottle on the left side is the CNTs/CA catalyst and bare CNTs on the right side. After dispersion for $16 \mathrm{~h}$, the CNTs/CA were completely mixed with each other in the ethanol solution, whereas the CNTs in the bottle with the absence of CA precipitated at the bottom. The CC was then immersed in the CNTs/CA solution and sonicated for $10 \mathrm{~min}$ so that the CC surface was completely coated with $\mathrm{CNTs} / \mathrm{CA}$. Because the reduction reaction at the cathode requires a large reduction current, the employment of the new catalyst CNTs/CA/CC supports increasing the reduction reaction current peak.
2.4. Fabrication of Self-Pumping EBC. The whole EBC stack and its components were shown in Figure 4, which consists of top and bottom end plates, PDMS gasket, cathode and anode flow field plate, current collectors, rubber gasket, the modified cathode and anode electrodes, and Nafion 117 membrane located in between the two electrodes composed as a sandwich structure. The cathode electrode is modified by CNTs/CA/CC, while the anode electrode was covered by $\mathrm{GOx}[\mathrm{TPP} / \mathrm{CS} / \mathrm{CC}]$. The fuel used as an anolyte is the mixed solution of $0.1 \mathrm{M}$ glucose, $0.1 \mathrm{M} \mathrm{NaCl}$, and $0.1 \mathrm{M}$ PBS, pH7, whereas the mixture of $0.1 \mathrm{M} \mathrm{K}_{3} \mathrm{Fe}(\mathrm{CN})_{6}$ and $0.1 \mathrm{M} \mathrm{PBS} \mathrm{pH} 7$ was used as catholyte.

There are three reservoirs in both top and bottom plate structures as shown in Figure 5. Reservoir 1 is the fuel supply and reservoirs 2 and 3 installed a well wettability cotton to intrigue the self-pumping structures. The fuel was added to reservoir 1 and transported to reservoir 2 by capillary force. By the end, the fuel was transported to the flow field. Sufficient fuel filling can be observed in the wettability of reservoir 3. Then the flow rate was determined by collecting the $500 \mathrm{~mm}^{3}$ fuel each time based on the elapsed time. The fuel eventually flowed through the anode flow field, where the oxidation reaction occurred and was then transported to the outlet reservoir 3 (Figure 5).

\section{Results and Discussion}

3.1. Electrode Hydrophilic Modification. For the self-pumping $\mathrm{EBC}$, the capillary force requires higher hydrophilic properties of the anode and cathode electrodes. By using Optical Contact Angle Meter Model 100SB, the original carbon 


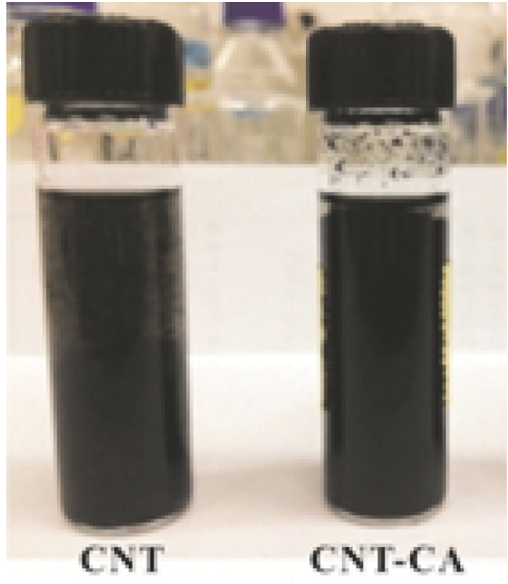

(a)

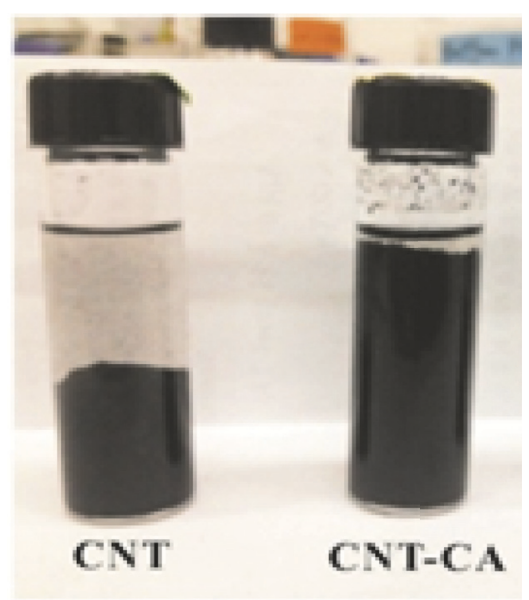

(c)

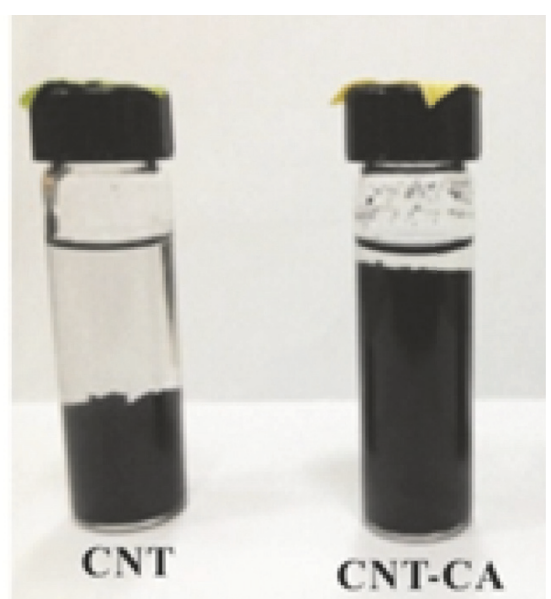

(b)

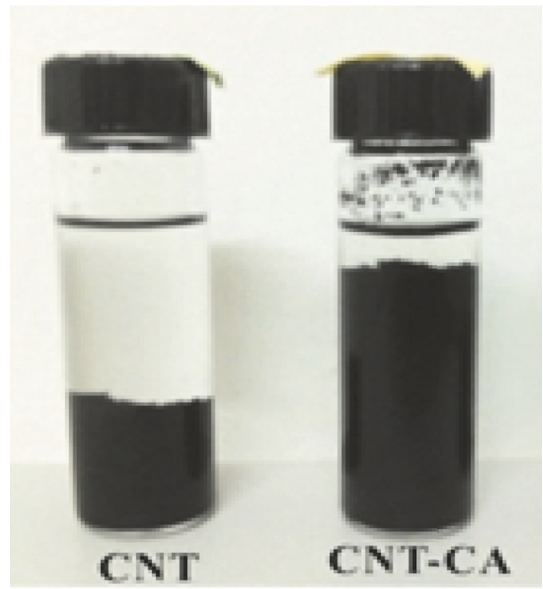

(d)

Figure 3: CNTs and CNTs/CA dissolved in ethanol. (a) 0 h. (b) 4 h. (c) 8 h. (d) 16 h.

clothes used as anode and cathode sides of the self-pumping EBC were hydrophobic with the surface contact angle of $138.80^{\circ}$ (Figure 6). To modify the surface of CC electrode being hydrophilic, the $\mathrm{CC}$ was immersed in the mixture of acids $\left(\mathrm{H}_{2} \mathrm{SO}_{4}: \mathrm{HNO}_{3}=3: 1\right)$ and then sonicated for $5 \mathrm{~min}$ to produce hydrophilic carboxyl functional group $(\mathrm{COOH})$ [22]. The contact angle measurement of the treated carbon materials was then observed to be nearly $0^{\circ}$ (Figure 6 ).

3.2. Electrode Structural Characterization. The chemical structures of GOx (curve a), CS/CC (curve b), and GOx[CS/CC] (curve c) were characterized by FTIR spectroscopy shown in Figure 7. The appearance of the characteristic absorption peak of the tested electrode (c) at $2873 \mathrm{~cm}^{-1}$ was different from (a) and (b) that represented the GOx enzyme successfully immobilized on the CS/CC electrode. In FTIR spectra of native GOx (curve a), the strong absorption peak at $3300 \mathrm{~cm}^{-1}$ is prescribed to the $\mathrm{N}-\mathrm{H}$ stretching as well as the typical peaks observed at 1650 and $1526 \mathrm{~cm}^{-1}$ which are characterized by amide I $(\mathrm{C}=\mathrm{O})$ stretching vibrations and amide II $(\mathrm{N}-\mathrm{H}$ and $\mathrm{C}-\mathrm{N}$ stretching) bands of native GOx. The FTIR spectrum showed the $\mathrm{CS} / \mathrm{CC}$ electrode as curve $\mathrm{b}$; the major peaks have $\mathrm{C}=\mathrm{O}$ and amide $\mathrm{NH}_{2}$ stretching vibration $\left(1080\right.$ and $1597 \mathrm{~cm}^{-1}$, resp.).

UV spectrophotometric method was developed in this study for quantification of the interaction ability of CA and CNTs in the CNTs/CA solution that was coated on the cathode electrode CNTs/CA/CC. Figure 8 showed the UV spectra of the supernatants of CNTs/CA adduct (curve a), free CA (b), and CNTs (c). The spectrum of CA in aqueous solution displayed a maximum absorption peak at $325 \mathrm{~nm}$. The UV spectra of the CNTs dispersed in aqueous solution exhibited strong absorbance at $210 \mathrm{~nm}$. It is obvious that the chemical absorption of the CNTs/CA composite displayed two strong peaks at $210 \mathrm{~nm}$ and $325 \mathrm{~nm}$ (curve a).

3.3. Electrochemical Characterization. To estimate the effect of the CNTs/CA composite on the electrochemical properties of the self-pumping EBC and to know whether the CNTs could enhance the redox current peak, CV curves of 


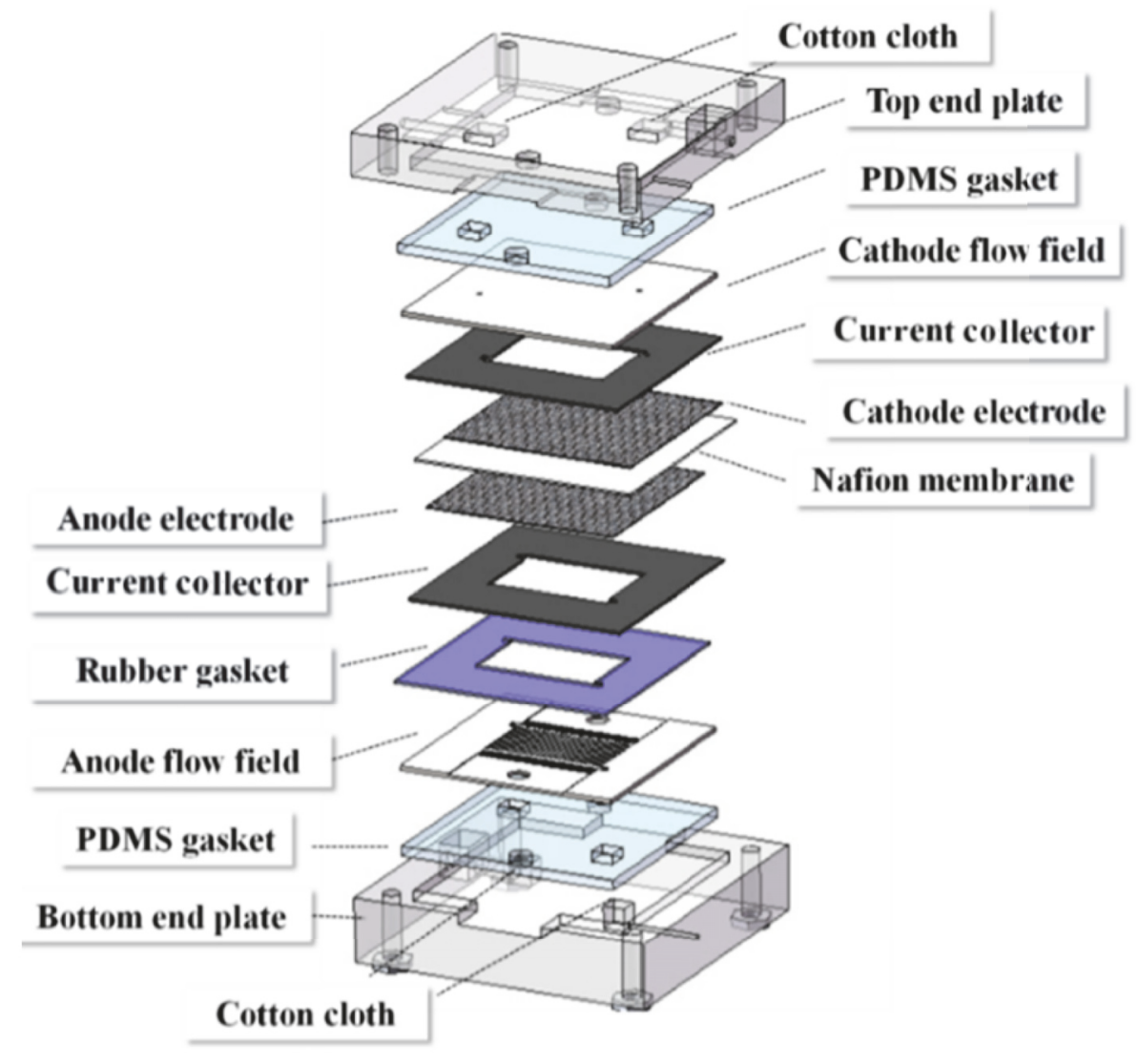

FIGURE 4: Single self-pumping EBC assembly as a sandwich structure and related components.

the $\mathrm{CNTs} / \mathrm{CC}, \mathrm{CA} / \mathrm{CC}$, and $\mathrm{CNTs} / \mathrm{CA} / \mathrm{CC}$ were measured under the saturated oxygen condition (Figure 9). The CVs of the catalysts were performed by using a 3-electrode system (Zennium E Electrochemical Workstation) with an $\mathrm{Ag} / \mathrm{AgCl}$ reference electrode, a Pt wire counter electrode, and the working electrode of the CNTs/CC, CA/CC, and CNTs/CA/CC submerged in the $20 \mathrm{ml}$ solution of $0.1 \mathrm{M}$ $\mathrm{K}_{3} \mathrm{Fe}(\mathrm{CN})_{6}$ and $0.1 \mathrm{M} \mathrm{KCl}$ at the potential range of $+0.7 \mathrm{~V}$ $0.3 \mathrm{~V}$ and the scan rate of $0.1 \mathrm{~V} . \mathrm{s}^{-1}$. The working electrode was prepared by loading catalyst (CNTs, CA, and CNTs/CA) on glassy carbon electrode (GCE, $3 \mathrm{~mm}$ in diameter). According to Figure 9, there was no current signal of the electrode with free CA (curve a) caused by no catalytic reaction of oxygen, while a small current peak of $30.9 \mu \mathrm{A}$ was found in the electrode with CNTs (curve b). However, when CNTs/CA/CC was tested under the same condition, the peak current was significantly higher than those of the CNTs/CC or CA/CC. Curve (c) showed the reduction reaction current peak of 139.1 $\mu \mathrm{A}$ at the potential of $0.12 \mathrm{~V}$. This phenomenon was the evidence of the effectiveness of coating CNTs/CA on the cathode electrode which enhanced the oxygen reduction reaction peak.

To further study the electrochemical reaction, the $\mathrm{CV}$ tests of the CNTs/CA/CC under different types of gases such as saturated argon, air, and saturated oxygen were measured (Figure 10). It is noted that the polarization curve of the CNTs/CA/CC electrode under the saturated oxygen
TABLE 1: The capillary driven fluid efficiency.

\begin{tabular}{|c|c|c|}
\hline $\begin{array}{l}\text { Flow rate } \\
(Q) / \text { efficiency }(\mu)\end{array}$ & Anode & Cathode \\
\hline $\mathrm{Q}_{\text {ideal }}\left(\mu \mathrm{ls}^{1}{ }^{1}\right)$ & 1.40 & 1.43 \\
\hline \multicolumn{3}{|c|}{ EBC without modified CNTs/CA/CC } \\
\hline $\mathrm{Q}_{\text {actual }}\left(\mu \mathrm{ls}-^{1}\right)$ & 0.499 & 0.764 \\
\hline$\mu_{\text {capillary }}(\%)$ & 35 & 53 \\
\hline \multicolumn{3}{|c|}{ EBC with modified CNTs/CA/CC } \\
\hline $\mathrm{Q}_{\text {actual }}\left(\mu \mathrm{ls}^{-1}\right)$ & 0.416 & 0.844 \\
\hline$\mu_{\text {capillary }}(\%)$ & 30 & 59 \\
\hline
\end{tabular}

condition (curve c) showed the highest current peak $(321.5 \mu \mathrm{A})$ compared with the other two cases.

3.4. Performance of Self-Pumping EBC. In the electrical performance tests of the whole cell, the $0.1 \mathrm{M}$ glucose mixed $0.1 \mathrm{M} \mathrm{NaCl}$ solution and $0.1 \mathrm{M} \mathrm{K}_{3} \mathrm{Fe}(\mathrm{CN})_{6}$ solution were fed into the anode and cathode, respectively, by the capillary force at different flow rates for both types of EBC (Table 1).

Theoretically, the ideal flow field solutions of cathode and anode were 1.43 and $1.40 \mu \mathrm{l} . \mathrm{s}^{-1}$, respectively. The measurement of the flow rate in the self-pumping $\mathrm{EBC}$ with modified CNTs/CA/CC electrode showed that the 

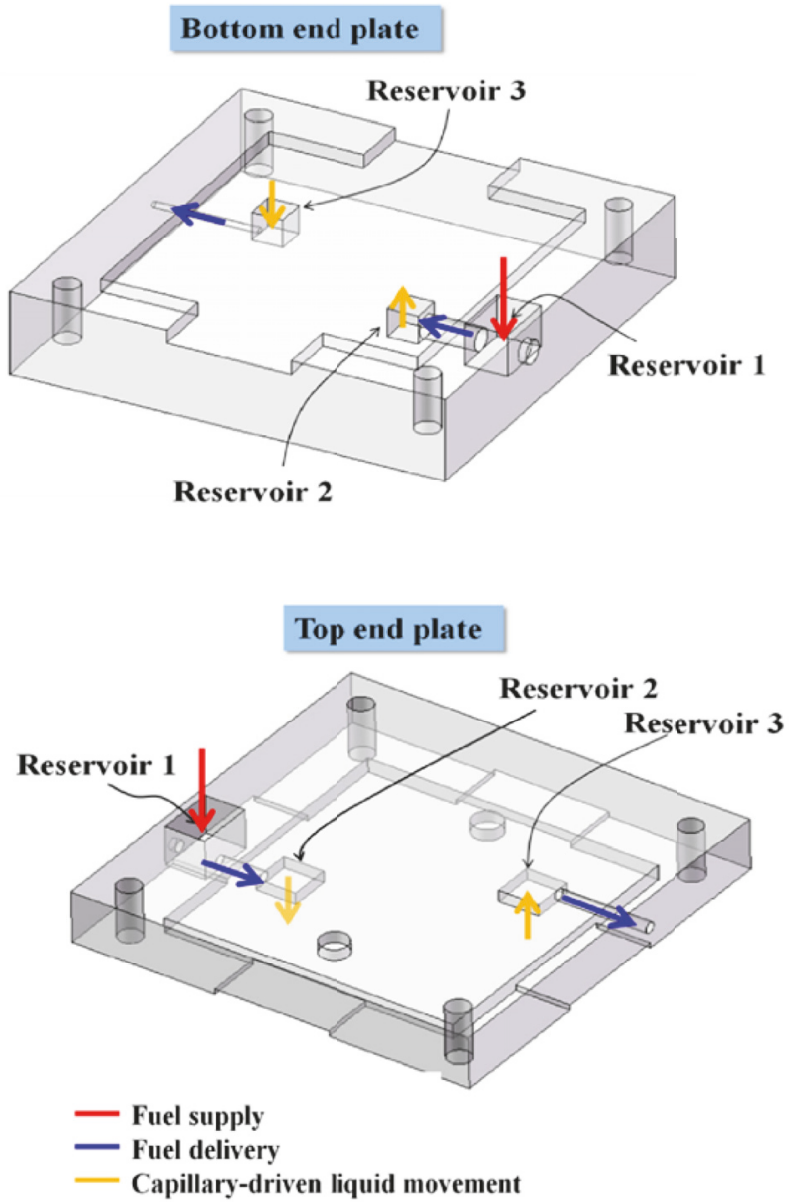

FIGURE 5: The schematic of the distributed fluid by the capillary effect.
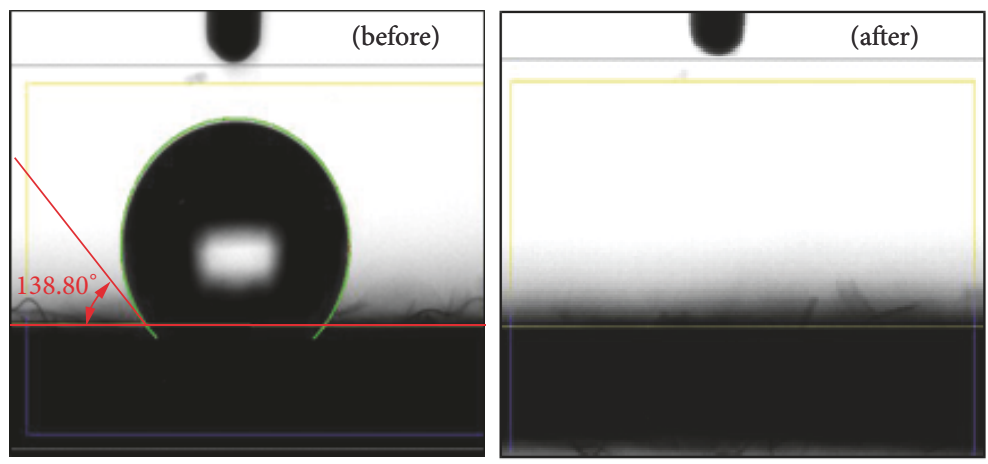

FIGURE 6: Contact angle measurement of carbon cloth for anodic and cathodic electrodes before and after modification.

flows in the cathode and anode flow field were 0.844 and $0.416 \mu \mathrm{l} . \mathrm{s}^{-1}$, respectively. The actual value is divided by the theoretical value; the capillary driven liquid efficiency for cathode flow field is 59\% and that for the anode flow field is $30 \%$. The performance of the self-pumping EBC with and without CNTs/CA/CC modified cathode electrode was evaluated by measuring their polarization curve and power density curve (Figure 11). The MPD of the EBC with the modified cathodic electrode was 0.592
$\mathrm{Wcm}^{-2}$ at $0.44 \mathrm{~V}$, which improved by $10 \%$ compared to the EBC with the unmodified cathode $\left(0.534 \mathrm{mWcm}^{-2}\right.$ at 0.42 $\mathrm{V})$.

Figure 12 showed the electric current recorded over a time interval of $20 \mathrm{~min}$ at the constant voltage. In this experiment, Reservoir 1 was continuously refilled when it ran out of fuel. The transient peak current fell to the steady state as the external circuit connected. After $75 \mathrm{sec}$ discharge, the current density maintained a steady state and was recorded every 3 


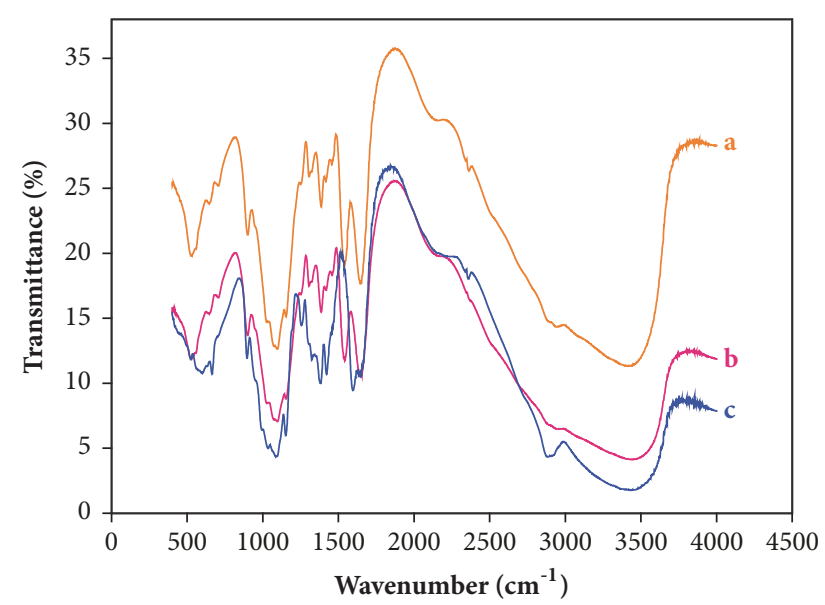

FIGURE 7: The FTIR spectrum of GOx (a), CC coated chitosan (b), and GOx immobilized CS/CC (c).

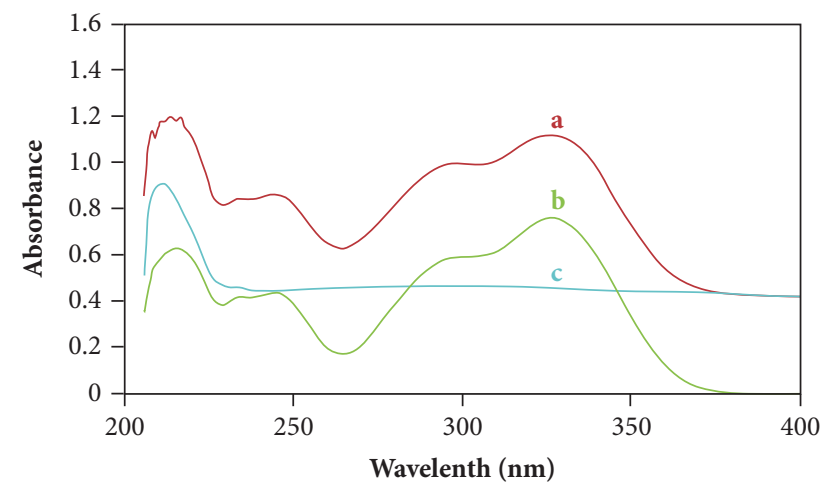

FIGURE 8: The absorbance peaks of the catalyst measured by UV spectrophotometer. (a) CNTs/CA. (b) CA. (c) CNTs.

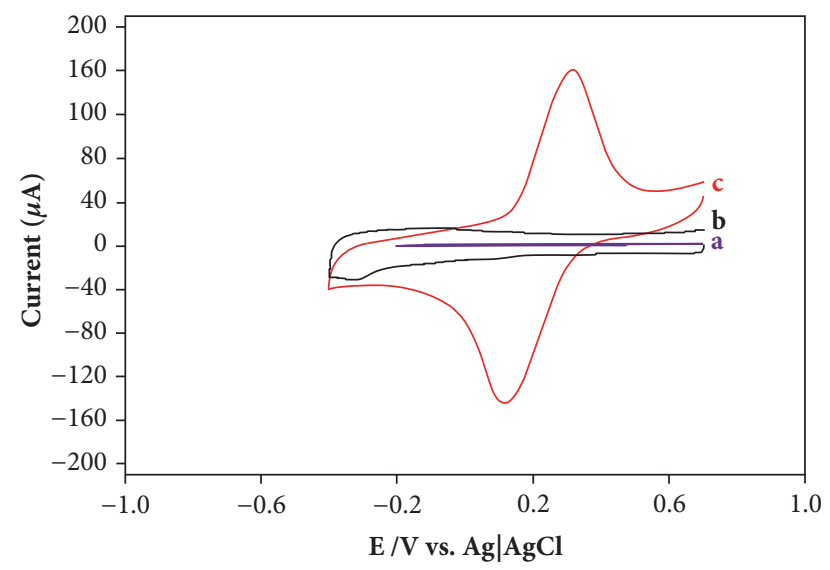

Figure 9: The CV curves of the electrode. (a) CA/CC. (b) CNTs/CC. (c) $\mathrm{CNTs} / \mathrm{CA} / \mathrm{CC}$.

min, which obtained an average value of $1.125 \pm 0.12 \mathrm{~mA} . \mathrm{cm}^{-2}$ and indicated the self-pumping EBS stability.

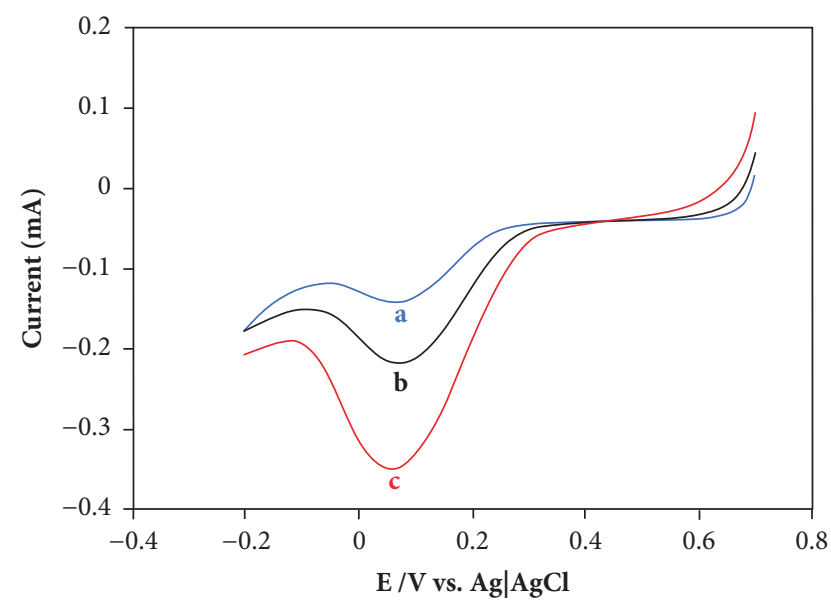

FIgure 10: The polarization curves of the CNTs/CA/CC cathodic electrode. (a) Saturated argon. (b) Air. (c) Saturated oxygen.

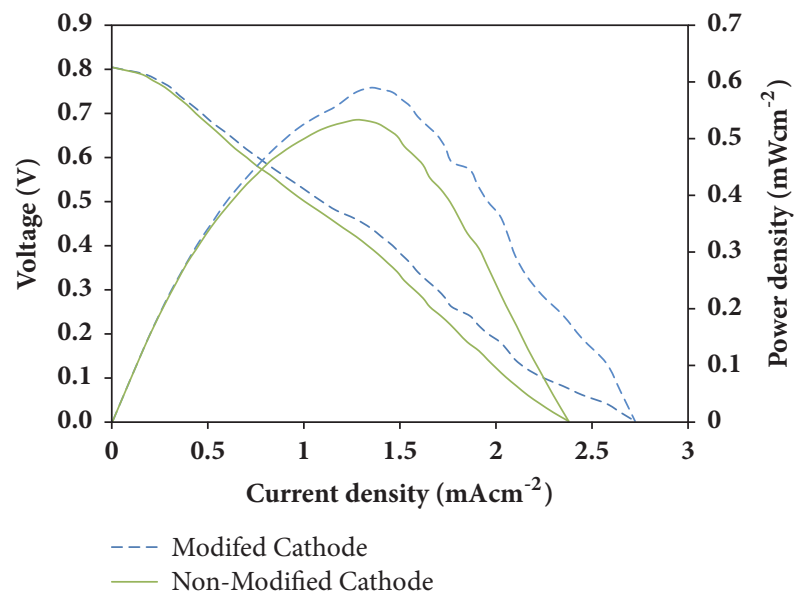

FIGURE 11: The polarization curve for self-pumping EBC with and without cathodic electrode CNTs/CA/CC.

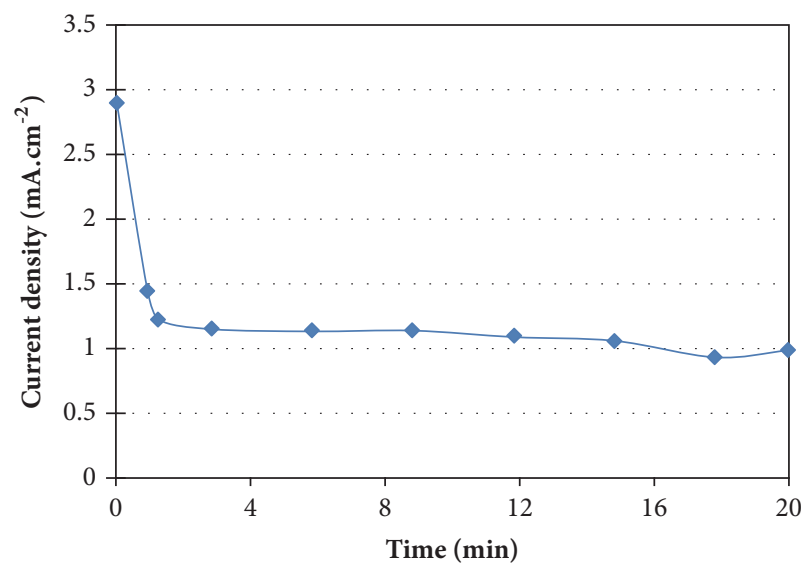

FIGURE 12: The current density versus elapsed time for the stability examination of the self-pumping EBC. 


\section{Conclusion}

A self-pumping EBC with the CNTs/CA/CC modified cathodic electrode for improving its performance was fabricated. According to the electrochemical evaluation, the CNTs/CA/CC electrode executed an excellent catalytic activity of the oxygen reduction reaction that contributed to increasing the current peak at $139.1 \mu \mathrm{A}$. Under different gases saturated $0.1 \mathrm{M} \mathrm{K}_{3} \mathrm{Fe}(\mathrm{CN})_{6}$ and $0.1 \mathrm{M} \mathrm{KCl}$ solutions, the highest current peak was observed in the presence of oxygen. Moreover, the MPD of the EBC with the CNTs/CA/CC cathodic catalyst was $10 \%$ higher than that of the EBC with the unmodified electrode with $0.592 \mathrm{mWcm}^{-2}$ at $0.44 \mathrm{~V}$ compared to $0.534 \mathrm{mWcm}^{-2}$ at $0.42 \mathrm{~V}$, respectively. By the EBC stability examination, the output current and power density were stable after $75 \mathrm{sec}$ discharge; the measured current density was $1.125 \pm 0.12 \mathrm{~mA} / \mathrm{cm}^{2}$ as the fuel was continuously pumped by the capillary force.

\section{Conflicts of Interest}

The authors declare that they have no conflicts of interest.

\section{Acknowledgments}

This work is funded by the Ministry of Science and Technology (MOST) of Taiwan (Grant 106-2221-E-005-074). Also, this work is supported in part by the Ministry of Education, Taiwan, under the Higher Education Sprout Project.

\section{References}

[1] I. Ivanov, T. Vidaković-Koch, and K. Sundmacher, "Recent advances in enzymatic fuel cells: Experiments and modeling," Energies, vol. 3, no. 4, pp. 803-846, 2010.

[2] Z. Ghassemi and G. Slaughter, "Biological fuel cells and membranes," Membranes, vol. 7, no. 1, 2017.

[3] X. Wang, D. Li, T. Watanabe et al., "A glucose/o-2 biofuel cell using recombinant thermophilic enzymes," International Journal of Electrochemical Science, vol. 7, no. 2, pp. 1071-1078, 2012.

[4] H. Sakai, T. Nakagawa, Y. Tokita et al., "A high-power glucose/oxygen biofuel cell operating under quiescent conditions," Energy \& Environmental Science, vol. 2, no. 1, pp. 133-138, 2009.

[5] K. H. Hyun, S. W. Han, W.-G. Koh, and Y. Kwon, "Fabrication of biofuel cell containing enzyme catalyst immobilized by layerby-layer method," Journal of Power Sources, vol. 286, pp. 197203, 2015

[6] Y. Chung, K. H. Hyun, and Y. Kwon, "Fabrication of a biofuel cell improved by the $\pi$-conjugated electron pathway effect induced from a new enzyme catalyst employing terephthalaldehyde," Nanoscale, vol. 8, no. 2, pp. 1161-1168, 2016.

[7] Y. Chung, Y. Ahn, D.-H. Kim, and Y. Kwon, "Amide group anchored glucose oxidase based anodic catalysts for high performance enzymatic biofuel cell," Journal of Power Sources, vol. 337, pp. 152-158, 2017.

[8] Y. Li, S. M. Chen, T. Y. Wu, S. H. Ku, M. A. Ali, and F. M. A. AlHemaid, "Immobilization of Laccase into poly (3, 4ethylenedioxythiophene) assisted biocathode for biofuel cell applications," International Journal of Electrochemical Science, vol. 7, pp. 11400-11413, 2012.

[9] S. C. Wang, F. Yang, M. Silva, A. Zarow, Y. Wang, and Z. Iqbal, "Membrane-less and mediator-free enzymatic biofuel cell using carbon nanotube/porous silicon electrodes," Electrochemistry Communications, vol. 11, no. 1, pp. 34-37, 2009.

[10] Y.-H. Ho, A. P. Periasamy, and S.-M. Chen, "Amperomteric ethanol biosensor based on alcohol dehydrogenase immobilized at poly-L-lysine coated carminic acid functionalized multiwalled carbon nanotube film," International Journal of Electrochemical Science, vol. 6, no. 9, pp. 3922-3937, 2011.

[11] X. Luo, J. Xu, Y. Du, and H. Chen, "A glucose biosensor based on chitosan-glucose oxidase-gold nanoparticles biocomposite formed by one-step electrodeposition," Analytical Biochemistry, vol. 334, no. 2, pp. 284-289, 2004.

[12] Y. Zhang, Y. Li, W. Wu, Y. Jiang, and B. Hu, "Chitosan coated on the layers' glucose oxidase immobilized on cysteamine/Au electrode for use as glucose biosensor," Biosensors and Bioelectronics, vol. 60, pp. 271-276, 2014.

[13] B. K. Shrestha, R. Ahmad, H. M. Mousa et al., "High-performance glucose biosensor based on chitosan-glucose oxidase immobilized polypyrrole/Nafion/functionalized multi-walled carbon nanotubes bio-nanohybrid film," Journal of Colloid and Interface Science, vol. 482, pp. 39-47, 2016.

[14] Y. Chung, Y. Ahn, M. Christwardana, H. Kim, and Y. Kwon, "Development of a glucose oxidase-based biocatalyst adopting both physical entrapment and crosslinking, and its use in biofuel cells," Nanoscale, vol. 8, no. 17, pp. 9201-9210, 2016.

[15] A. B. Moghaddam, M. R. Ganjali, R. Dinarvand, P. Norouzi, A. A. Saboury, and A. A. Moosavi-Movahedi, "Electrochemical behavior of caffeic acid at single-walled carbon nanotube:graphite-based electrode," Biophysical Chemistry, vol. 128, no. 1, pp. 30-37, 2007.

[16] H. Filik, G. Çetintaş, A. A. Avan, S. Aydar, S. N. Koç, and I. Boz, "Square-wave stripping voltammetric determination of caffeic acid on electrochemically reduced graphene oxideNafion composite film," Talanta, vol. 116, pp. 245-250, 2013.

[17] Y. Yang and Y. C. Liang, "Passive direct methanol fuel cell system with adaptive fuel concentration control based on liquid surface tension," in Proceedings of the International Conference on Power Engineering, Energy and Electrical Drives, POWERENG 2007, pp. 365-370, Portugal, April 2007.

[18] Q.-Z. Lai, G.-P. Yin, and Z.-B. Wang, "Effect of anode current collector on the performance of passive direct methanol fuel cells," International Journal of Energy Research, vol. 33, no. 8, pp. 719-727, 2009.

[19] W. Huang, Q. Liu, and Y. Li, "Capillary Filling Flows inside Patterned-Surface Microchannels," Chemical Engineering \& Technology, vol. 29, no. 6, pp. 716-723, 2006.

[20] Y.-F. Tsai, C.-J. Shieh, and H. Yang, "Capillary force pumping fluid for glucose oxidase enzymatic fuel cells," Microsystem Technologies, vol. 23, no. 9, pp. 3927-3935, 2017.

[21] M. J. E. Fischer, "Amine coupling through EDC/NHS: a practical approach.," Methods in Molecular Biology (Clifton, N.J.), vol. 627, pp. 55-73, 2010.

[22] G. Zhang, S. Sun, D. Yang, J.-P. Dodelet, and E. Sacher, "The surface analytical characterization of carbon fibers functionalized by H2SO4/HNO3 treatment," Carbon, vol. 46, no. 2, pp. 196205, 2008. 

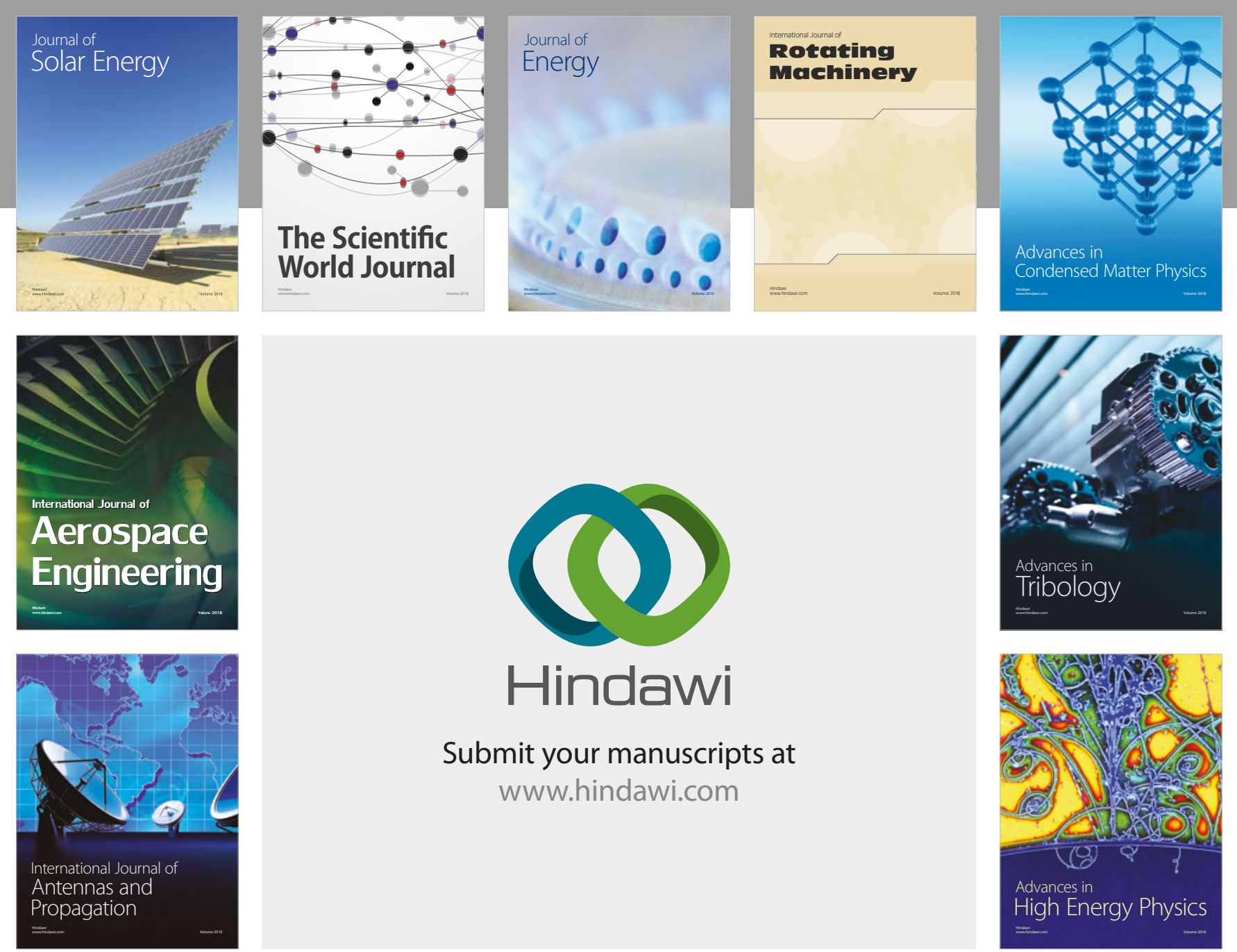

Submit your manuscripts at

www.hindawi.com
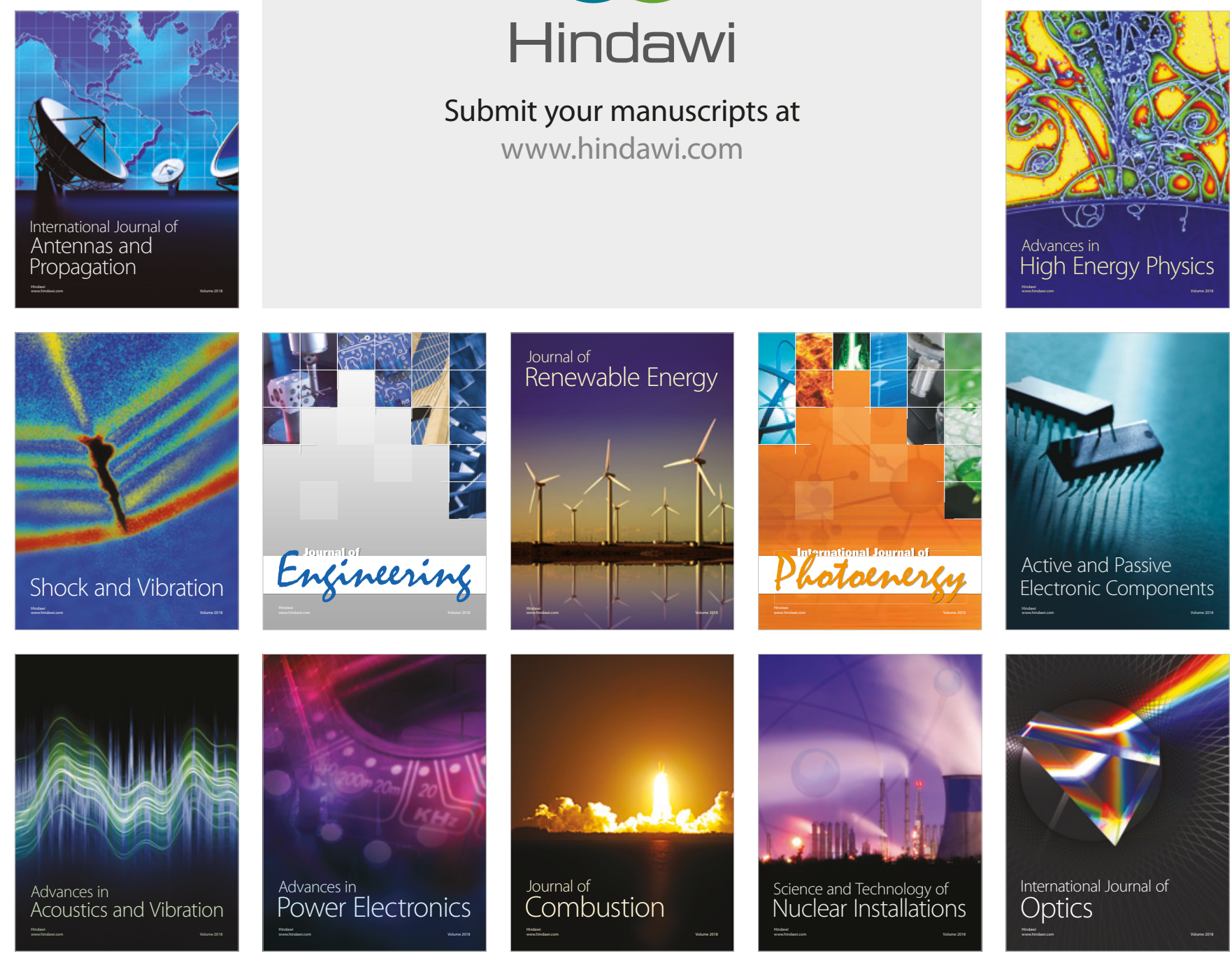